\title{
COMMISSION 33: STAR CLUSTERS AND ASSOCIATIONS
}

\section{(AMAS STELLAIRES ET ASSOCIATIONS)}

\section{PRESIDENT: G. Meylan}

VICE-PRESIDENT: A. Sarajedini

BOARD: R. Cannon, V. Castellani, K. Cudworth, G. Da Costa, D. Hatzidimitriou, C. Lada, R. Spurzem

\section{Introduction}

Commission 37 held a brief business session at 9:00 am on Monday, July 21, 2003, followed by a scientific session for the remainder of the morning.

Both business and scientific sessions were jointly organized in the framework of Division VII by its two IAU Commissions in order to have simultaneously all members of the Division attending the same sessions.

\section{New Division Board}

The meeting agreed with the following new Commission Board:

- President: A. Sarajedini (USA)

- Vice President: R. Spurzem (Germany)

- R. Cannon (Australia)

- V. Castellani (Italy)

- K. Cudworth (USA)

- G. Da Costa (Australia)

- L. Deng (China)

- M. Giersz (Poland)

- D. Hatzidimitriou (Grece)

- C. Lada (USA)

- G. Meylan (USA)

At the General Assembly, 23 new members were added to the Commission, taking the total membership to approximately 265 members.

\section{Scientific Session: THE FORMATION OF THE GALACTIC HALO}

See Division VII report. 